\title{
Mental health in Armenia
}

\section{Armen Soghoyan, ${ }^{1}$ Arega Hakobyan, ${ }^{2}$ Harutyun Davtyan, ${ }^{3}$ Marietta Khurshudyan ${ }^{4}$ and Khachatur Gasparyan ${ }^{5}$}

\author{
${ }^{1}$ Yerevan State Medical University, Yerevan, Armenia, email soghoyan@yahoo.com; \\ ${ }^{2} \mathrm{Head}$ of the Outpatient Department, Avan Mental Hospital; ${ }^{3} \mathrm{Head}$ of the Men's Department, Avan Mental Hospital; \\ ${ }^{4}$ Expert, National Assembly, Standing Committee on Health Issues, Yerevan; ${ }^{5}$ Yerevan State Medical University, Yerevan, Armenia
}

\begin{abstract}
A rmenia is a landlocked mountainous country between the Black Sea and the Caspian Sea, in the southern Caucasus. It shares borders with Turkey to the west, Georgia to the north, Azerbaijan to the east, and Iran and the Nakhchivan exclave of Azerbaijan to the south. Its total area is $29743 \mathrm{~km}^{2}$. A former republic of the Soviet Union, Armenia is a unitary, multi-party, democratic nation state with an ancient cultural heritage. Armenia prides itself on being the first nation formally to adopt Christianity (in the early 4th century).

According to the census of 2001, the population of Armenia is 3219200 but the July 2009 estimate is 2967004 . The population of Armenia is homogeneous - Armenians form $97.9 \%$ of the population. The spoken language is Armenian. The main religious group is Armenian Apostolic $(94.7 \%)$. The age structure is as follows: 14 years or under, $18.2 \%$ (male 289119, female 252150); 15-64 years, $71.1 \%$ (male 986764, female 1123708 ); 65 years and over, $10.6 \%$ (male 122996, female 192267 ) (2009 estimates). The population growth rate is estimated to be $0.03 \%$ per year, the birth rate per 1000 population to be 12.53 and the death rate 8.34 per 1000 . The infant mortality rate is 20.21 per 1000 live births. Life expectancy at birth is 72.68 years $(69.06$ years for males, 76.81 years for females) and healthy life expectancy at birth 66.7 years. A majority of the population (64.2\%; 2066700 persons) resides in urban areas. Most adults (99.5\%) are literate.
\end{abstract}

\section{Healthcare system}

As a post-Soviet state, the Republic of Armenia inherited a health system organised according to the Semashko model, with guaranteed free medical assistance and access to a comprehensive range of medical care for the entire population. The system was highly centralised, with vertical management dominating. Financial and other allocations were based on national norms and failed to take account of population health needs. There was an emphasis on structural and quantitative indicators, resulting in the expansion of physical capacity, an oversupply of health personnel and a surplus of hospital beds, along with an unequal distribution of resources.

Since independence, the health system in Armenia has undergone numerous changes. Following the decentralisation of public services, the ownership of health services has been devolved to local and provincial governments.
The population, especially those in need, has limited access to health services. The services delivered are sometimes of questionable quality. Many health facilities, especially in rural areas, lack modern medical technology and human resources.

Armenia is increasingly engaged in changing the system from one that emphasises the treatment of disease and response to epidemics to one that emphasises prevention, family care and community participation. Although the emphasis of reform has been on increased state budgets and more efficient use of resources, the majority of financing is still derived from out-of-pocket payments, both formal and informal. The shift towards an orientation on primary care is noticeable, with gradually increased roles for health workers to influence the determinants of health (Hakobyan et al, 2006).

\section{Mental health legislation}

After 1991, when Armenia became independent, Parliament passed a few laws on public health and healthcare but no law on mental health, until comparatively recently. Up until 2004, mental healthcare in Armenia was regulated by an order of the Minister of Health of the USSR, although the order did not have power of law. In September 1998, the Board of the Mental Health Foundation began to draft a mental health law and to publish a series of materials on mental health legislation. In January 1999, a draft Bill was presented to the Minister of Health and mental health is now regulated by the Law on Psychiatric Care, adopted on 25 May 2004. This regulates involuntary treatment, the civil and human rights of people with mental disorders, and other mental health issues. The Law was amended in 2006.

The criminal law also has a bearing on mental health, mainly in relation to involuntary treatment.

Amendments to the Law on Psychiatric Care have been proposed by the National Assembly of the Republic of Armenia. These focus on treatment facilities and service structures as well as human rights. It would also be useful if future revisions could address areas of potential conflict between mental health specialists and other service providers and patients' interests. For example, the terms of voluntary and involuntary admissions have not been clearly defined within the legislation. A maximum duration of involuntary admission is fixed by criminal law but is not stated in the Law 
on Psychiatric Care. Similarly, the rights of family members and other carers are not stated.

Policy on mental health is still not well developed and there is no governmentally approved and adopted mental health programme in Armenia. General approaches to mental health require modernisation, as some strategies and practices have been retained from the Soviet period.

Another concern is that there is no emergency/disaster preparedness plan for mental health (WHO Regional Office, 2007).

\section{Mental health services}

Because of the country's transition from the Soviet period, the mental health system in Armenia has changed significantly over the past two decades.

Mental health services in Armenia are lacking and those available are poorly integrated into the primary care system. The current system focuses on in-patient care. There is a lack of trained social workers and other mental health professionals, which limits the potential for service provision at community level. Essentially, psychiatric care is still exclusively provided in specialised mental health institutions, including hospitals and social psychoneurological centres. Currently, only $3 \%$ of the overall public healthcare budget is given to mental health. In turn, around $88 \%$ of the mental health expenditure is on mental hospitals.

The essential psychotropic medicines are provided free of charge to all registered patients. In addition, all severe and some mild mental disorders are covered by social insurance schemes under which patients get free treatment. Also, those who are recognised to have chronic disorders get financial support from the government in the form of a disability pension.

There are 135 hospitals in Armenia with 13100 beds: 99 hospitals with 8732 beds are in the public sector (that is, under the management of the Ministry of Health), 27 are private and 9 are run by other governmental bodies or departments. An overcapacity of in-patient beds leads to the unnecessary admission of individuals with chronic illness who would better be treated in out-patient settings. Unfortunately, there is no systematic approach to developing community mental health services except for some small-scale pilot projects, usually supported by international organisations (Hakobyan et al, 2006).

There are 467 primary healthcare clinics in Armenia, of which 380 are physician-based in the public sector and 69 physician-based in the private sector, while the other 18 are under other governmental bodies or departments.

Psychosocial rehabilitation is underrepresented in the mental hospitals and few patients receive psychosocial interventions. In contrast, psychotropic medicine is highly accessible in in-patient mental health facilities. All mental hospitals have available at least one psychotropic medicine of each therapeutic class (antipsychotic, antidepressant, mood stabiliser, anxiolytic, or anti-epileptic).

There are only five out-patient mental health facilities. All of them are organisationally integrated with mental hospitals; two are for children and adolescents only. There are 1311.5 users per 100000 general population in these out-patient facilities. Of these out-patients, $29 \%$ are female and $2 \%$ are children and adolescents. Of all those treated in out-patient facilities, $28 \%$ have a primary diagnosis of schizophrenia or schizotypal and delusional disorders.

Three mental health facilities provide day care, all for adults only (there are no day treatment facilities for children and adolescents). Day treatment mental health facilities treat 9.5 users per 100000 population.

In general, in Armenia mental health and mental disorders in children and adolescents are not regarded with anything like the same importance as their physical health. Although some programmes have been initiated recently concerning general mental health, there are no plans that would include children and adolescents.

\section{Training, education and research}

In 2008, per 100000 population, 11.1 medical doctors (not specialised in psychiatry) graduated in Armenia, as did 50 nurses (not specialised in psychiatry). There are no psychiatrists, psychologists or nurses and social workers with more than 1 year of training in mental healthcare. Around 20\% of psychiatrists emigrate to other countries within 5 years of the completion of their training.

In 2008, no mental healthcare staff received more than 2 days of refresher training in the rational use of drugs, psychosocial interventions or child and adolescent mental health issues. The major problem for mental health education, as in the field of public health in general, is that there is no regular provision of continuous medical education for psychiatry and clinical psychology. The government supports training for professionals once in every 5 years, but even then this training is generally formal and psychiatrists are not satisfied with it.

International exchange experience is lacking at governmental level. This means that new trends in treatment and drugs are neglected. There are some donor organisations supporting international exchange for a few professionals, and others try to participate in internationl conferences and workshops using their personal resources.

Mental health research is underdeveloped and lacks governmental support. There is, though, some research based on the interests of individual investigators or some priorities suggested by donor organisations. This tends to be focused on epidemiological studies in community samples, epidemiological studies in clinical samples, biology and genetics, policy, programmes, financing/economics, and pharmacological, surgical and electroconvulsive interventions.

\section{Sources}

Hakobyan, T., Nazaretyan, M., Makarova, T., et al (2006) Armenia: health system review. Health Systems in Transition, 8(6), 1-180.

National Statistical Service of the Republic of Armenia, at http://www. armstat.am (accessed May 2009).

Soghoyan, A. (2003) Psychiatric care in Yerevan. Mental Health Reforms, 1, 16-19.

Van Baelen, L., Teocharopoulos, Y. \& Hargreaves, S. (2005) Mental health problems in Armenia: low demand, high needs. British Journal of General Practice, 55, 64-65.

WHO Regional Office (2007) Evaluation of Emergency/Disaster Preparedness Capacities of Armenia. WHO. 